\title{
UMA ANÁLISE SOBRE O DESENVOLVIMENTO DO PRIMEIRO COMANDO CAPITAL A PARTIR DA EFETIVAÇÃO DO DIREITO PENAL DO INIMIGO NA REALIDADE DO CÁRCERE BRASILEIRO
}

Izadora Nogueira Nunes

Graduanda de Direito no Centro Universitário do Pará CESUPA, com período de 1 semestre de intercâmbio no programa ERASMUS na Universidade Do Porto - FDUP. E-mail: izadorannunes@gmail.com

\section{RESUMO}

O presente trabalho tem objetivo de contribuir para um modelo de segurança pública mais garantista e racional, demonstrando as consequências que o punitivismo exacerbado e a flexibilização de direitos podem desencadear à segurança pública em geral. O advento da globalização foi ponto de partida para aplicação de um modelo de segurança baseado na perseguição do criminoso, como solução imediata para conter os novos meios de riscos surgidos a partir dessa nova era. Assim, foi possível identificar a aplicação de um Direito Penal não humano, o Direito penal do Inimig, teorizado por Gunther Jakobs, que autoriza essa atuação Estatal coercitiva e autoritária para com os que são estigmatizados como elementos de alta periculosidade, que ameaçam a ordem social. Tal teoria pode ser identificada tanto no momento do processo penal, que é constantemente flexibilizado para levar à condenação, assim como dentro dos estabelecimentos prisionais, justamente por serem os lugares onde esses sujeito são levados para pagar pelos crimes que cometeram. $\mathrm{O}$ estigma destinado ao encarcerado, portanto, faz com que a pena se torne uma verdadeira tortura em razão das constantes violências dentro das prisões além da estrutura precária que esses lugares apresentam. Tais condições foram fundamentais para um processo de auto-organização da população carcerária, impulsionada por um sentimento de injustiça e vingança, através de uma organização paralela que foi justamente o Primeiro Comando Capital. Portanto, a aplicação de uma estratégia de segurança pública extremamente punitivista teve efeito totalmente contrário ao que se objetivava, na medida em que a macrocriminalidade se espalhou por todo o país e hoje se apresenta altamente poderosa e articulada.

PALAVRAS-CHAVE: Estado. Inimigo. Cidadão. Segurança. 


\title{
THE LIMITS IN TRAINING TEACHERS OF FOREIGN LETTERS AT UFPA TO WORK IN INCLUSIVE EDUCATION: A CURRICULAR ANALYSIS
}

\begin{abstract}
This paper aims to contribute to a more secure and rational public security model, demonstrating the consequences that exacerbated punitivism and the relaxation of rights can trigger to public security in general. The advent of globalization was the starting point for the application of a security model based on the persecution of the criminal as an immediate solution to contain the new means of risks arising from this new era. Thus, it was possible to identify the application of a non-human Criminal Law, the Inimig Criminal Law, theorized by Gunther Jakobs, which authorizes this coercive and authoritarian State action towards those who are stigmatized as elements of high danger, which threaten the social order. Such a theory can be identified both at the time of criminal prosecution, which is constantly being flexed to lead to conviction, as well as within prisons, precisely because these are places where these subjects are taken to pay for the crimes they have committed. The stigma attached to imprisonment, therefore, makes the sentence a real torture because of the constant violence within prisons beyond the precarious structure that these places present. Such conditions were fundamental to a process of selforganization of the prison population, driven by a sense of injustice and revenge, through a parallel organization that was precisely the First Capital Command. Therefore, the application of an extremely punitive public security strategy had the opposite effect, as macro-crime spread throughout the country and today is highly powerful and articulate.
\end{abstract}

KEYWORDS: State. Enemy. Citizen. Safety.

\section{INTRODUÇÃO}

Os avanços tecnológicos permitiram significativas mudanças no modo de vida das populações ocidentais a partir da metade do século XX: a diminuição da noção de tempo/ espaço, a interdependência econômica entre as nações e o processo de unificação do espaço global caracterizaram o nascimento de uma nova era marcada pela supressão das barreiras geográficas entre os países, na qual os diversos extremos do globo tem sua economia, política e cultura compartilhadas.

Com isso, também houve o surgimento de demandas típicas desse novo contexto, que passaram a ser reivindicadas em razão do potencial lesivo que representavam. A destruição 
ambiental e seus efeitos globais, pobreza mundial, reclamação por direitos humanos, criminalidade urbana, crimes tecnológicos, entre outros meios de risco, foram para o centro da discussão social por representarem questões inéditas a serem atendidas. A constante imprevisão e ausência de controle sobre as consequências que esses riscos trariam, assim como sobre a forma de tutela-los fez nascer um sentimento de vulnerabilidade no meio social, por estar sempre a mercê de um futuro incerto.

Foi a partir desse marco de grandes mudanças em escala mundial que a criminalidade passou a ser o centro da atenção estatal para conter o sentimento de insegurança, e, em razão disso, o Brasil adotou políticas de segurança pública extremamente autoritárias, visando conter esses novos meios de risco, dentre elas: a criação de novas leis penais referentes a demandas que surgiram a partir do mundo globalizado, endurecimento das que já existiam e uma política de encarceramento massivo como forma de combate a criminalidade. De acordo com SANTOS; GONTIJO, et al $(2015,110)$, o investimento em segurança publica nos municípios cresceu $120 \%$ entre 2003 e 2013, embora tais municípios tenham crescido em apenas $11 \%$ durante esse período.

Segundo as palavras de MANSO e DIAS (2017, p. 12):

Tanto no Rio como em São Paulo, as décadas de 1960 e 1970 foram marcadas por mudanças que incluíam a intensa e desordenada urbanização das cidades, a recessão econômica e a exaustão de um modelo de desenvolvimento baseado na indústria, produzindo redução no emprego formal e na regularidade do trabalho. É nesse quadro estrutural instável, marcado pela sensação de vulnerabilidade e medo diante das mudanças, que o universo do crime foi para o centro do debate cotidiano na esfera pública. (PCC, sistema prisional e gestão do novo mundo do crime no Brasil.

Por outro lado, sem a devida adequação dos estabelecimentos prisionais para essa nova população que ingressava no cárcere, a superlotação passou a fazer parte da realidade de muitos desses lugares, problema que perdura até os dias atuais conforme pode se constatar a partir do Monitor de Violência do G1, que afirma "Há hoje 704.395 presos para uma capacidade total de 415.960, um déficit de 288.435 vagas. Se forem contabilizados os presos em regime aberto e os que estão em carceragens da Polícia Civil, o número passa de 750 mil".

A relação desproporcional entre a quantidade de presos e o número de vagas que as prisões suportam trouxeram para esses estabelecimentos uma serie de consequências estruturais. Em meados de 2007 e 2008, uma Comissão Parlamentar de Inquérito (CPI) 
organizada pela Câmara dos deputados investigou o sistema prisional brasileiro, chegando a conclusões um tanto intrigantes. Segundo o relatório, os problemas dentro das penitenciarias vão desde a dificuldade ao acesso a agua até péssimas condições alimentares. Nas palavras de BARCELLOS (2010, p. 42-43):

É frequente que os presos não tenham acesso à água em quantidades minimamente razoáveis - seja para higiene, seja para consumo. É igualmente frequente que as celas sejam contaminadas por esgoto corrente e que nelas haja lixo em caráter permanente, inclusive fezes e urina mantidas em garrafas de refrigerantes nos cantos das celas, já que não há instalações sanitárias su cientes.

(...)

O relatório da CPI descreve que, como regra, não há colchões ou, quando eles existem, são em quantidade insu ciente. A comida, em geral, é pouca e de péssima qualidade, quando não é servida estragada. Em muitos presídios ela é servida em sacos plásticos e os detentos têm de comer com as mãos, já que não há talheres. Roupas também não são fornecidas. A carência desses elementos (colchões, rou- pas, comida etc.) fomenta um amplo mercado negro no interior desses estabelecimentos. Acrescente-se a isso o fato de não haver controle térmico das celas, que podem chegar a temperaturas próximas a 50 graus no verão (sic).

Portanto, embora o governo tenha investido numa política de segurança publica extremamente punitivista, não teve como mesma prioridade preparar os estabelecimentos prisionais para essa nova população carcerária que ingressou e tampouco demonstrou se importar com as necessidades básicas dos encarcerados, o que tornou esses estabelecimentos verdadeiros antros de tortura por conta da estrutura precária e desumana.

O Atlas de Violência do IPEA do ano de 2018 aponta que, a apesar da extensa política de fortalecimento a segurança publica e encarceramentos massivos, a taxa de homicídios no Brasil dobrou num período de 20 anos, passando, em números, de 38.929 homicídios em 1996 para 62.517 em 2016.

Da mesma forma, os crimes contra o patrimônio, mais especificamente de roubo, também cresceu consideravelmente nos últimos anos. O Atlas indica que em 2007 a quantidade roubos no Brasil foi de 302.954, em números absolutos, ao passo que em 2012 essa quantidade subiu para 841.663. Portanto, houve um crescimento de mais de $100 \%$ na quantidade de roubos em apenas cinco anos no país.

Assim, pode-se constatar que, apesar dos investimentos, o Brasil não conseguiu diminuir a criminalidade no país, e tampouco mantê-la estável. Tal contradição será estudada no 
presente artigo relacionando-a as condições desumanas existentes nas prisões

\section{ENTENDIMENTO DOUTRINÁRIO}

A construção de uma educação inclusiva é resultado de esforços para por fim na segregação que ocorria no sistema de ensino até o início do século XXI, no qual os alunos com deficiência eram separados dos alunos das turmas regulares, o que ocorria devido à existência da escola regular e da escola especial. E nesse sentido,

Jakobs define o direito penal do inimigo como uma forma de atuação coercitiva frente aos indivíduos que não oferecem a segurança cognitiva que o Estado necessita para que se mantenha a ordem ou que não são interessantes ao Estado por qualquer motivo politico ou econômico, sendo assim, considera legitima a utilização de um Direito Penal excepcional destinado aqueles que ameacem o ordenamento jurídico, e, portanto, a autoridade Estatal.

O Estado, então, é autorizado a agir de tal forma em razão de um bem maior, que seria a segurança publica e a proteção dos cidadãos. Segundo JAKOBS (2007, p. 42):

Quem não presta uma segurança cognitiva suficiente de um comportamento pessoal, não so não pode esperar ser tratado ainda como pessoa, mas o estado não deve trata-lo, como pessoa, já que do contrario vulneraria o direito a segurança das demais pessoas. Portanto, seria completamente errôneo demonizar aquilo que aqui se tem denominado como Direito penal do inimigo.

Portanto, para Jakobs o Direito Penal do Inimigo é importante para que se mantenha a segurança publica, uma vez que tais sujeitos representam uma ameaça, e por isso devem ser submetidos a medidas de segurança autoritárias e coercitivas visando a estabilidade social e manutenção do poder estatal.

Uma das principais características da atuação do direito penal do inimigo é a criminalização dos atos preparatorios, uma vez que meras condutas passam a ser penalizas por representarem uma ameaça. Dessa forma, o Estado passa a ter uma atuação mais autoritária no intuito de identificar a existência de uma conduta delitiva eminente, ou seja, a mera probabilidade do dano. Segundo JAKOBS (2007, p.44) "o ponto de partida ao qual se ata a regulação é a conduta não realizada, mas só planejada, isto é, não o dano a vigência da norma que tenha sido realizada, mas o fato futuro".

ZAFARONNI, por outro lado, afirma que essa forma de atuação do direito penal baseado no não cidadão induz a supressão do Estado de Direito (2007, página), uma vez que, 
ao teorizar o direito penal do inimigo, Jakobs o vê de forma limitada, ou seja, sua atuação é destinada somente a sujeitos muito específicos (como os terroristas), portanto é aplicado em situações excepcionais, enquanto que o que deve prevalecer é o direito penal do cidadão. Zaffaroni conceitua essa teorização como estática , em razão de sua excepcionalidade. Ocorre que, ao se analisar a aplicação do Direito Penal do Inimigo na realidade, o que se observa é a ampliação dessa forma de atuação autoritária conforme a necessidade do Estado, ou seja, enquanto houver conveniência política para aplicar o direito penal do inimigo, o Estado atuara dessa forma.

De acordo com ZAFFARONI, essa forma de atuação induz a supressão do Estado de direito uma vez que, se o Estado considerar-se ameaçado, ele julgara necessário a aplicação do direito penal do inimigo pautado pelo discurso de preservação a segurança publica. Segundo ZAFFARONI (2007, p. 166-167):

A partir de uma visão estática do poder, ou seja, da fotografia, é possivel pensar que, se concedermos um espaço limitado ao direito penal do inimigo, ou seja, se entregarmos um grupo de pessoas ao poder conforme o modelo do Estado de policia, e de forma limitada, as pulsos desse modelo cessarão. Todavia, não é isso que acontece na realidade dinâmica do poder, no qual todo espaço que se concede ao Estado de policia é usado por este para estender-se até chegar ao estado absoluto.

Em contrapartida, essa necessidade é demasiadamente subjetiva, já que dependendo da conveniência política do momento, o Estado mudará o foco de sua atuação coercitiva para sujeitos diversos.

A atuação do direito penal do inimigo ao caso concreto desencadeia o que Schimitt denomina como guerra suja contra esses inimigos, uma vez que é uma guerra não pautada pelos princípios do direito internacional humanitário de Genebra, e sim por uma atuação Estatal totalmente arbitraria contra aqueles que considera, por conveniência, os inimigos. Nas palavras de ZAFFARONI (2007, p. 145):

Está se introduzindo com isso um conceito espúrio ou particular de guerra premente e irregular, porque se trata de um inimigo que, por atuar fora das normas que devem ser cumpridas na guerra propriamente dita, ingressa no direito ordinário de um Estado que não está estritamente em guerra.

Assim, o Estado atua de forma coercitiva a qualquer sujeito ou classe que possa representar 
uma ameaça a sua autoridade, criando uma verdadeira guerra permanente, confundida com poder punitivo, na qual não há limite jurídico.

\section{O DIREITO PENAL DO INIMIGO NA REALIDADE DO CÁRCERE BRASILEIRO}

Ao longo da historia o Direito Penal sempre designou inimigos para serem alvo das condutas repressivas do governo pelo potencial lesivo que representavam ao Estado, ou por serem considerados descartáveis a partir de uma perspectiva econômica. Na idade media, em razão da forte influencia da Igreja Católica, a classe dos inimigos era representada pela figura do Satã. Entretanto, visto a impossibilidade de penaliza-lo, as mulheres eram tidas como os sujeitos que esse inimigo incorporava para exercer suas atrocidades na Terra. Por isso a elas era imputado o status de inimigo, de forma que foram perseguidas e vigiadas durante todo esse período por conta do "potencial demoníaco".

Durante a revolução mercantil, os colonizados foram tidos como inimigos por serem considerados uma afronta ao estilo de vida padrão da Europa, de forma que eram visto como seres inferiores que deviam ser aniquilados. O genocídio aos povos tradicionais que ocorreu tanto na América do Norte como do Sul exemplifica esse caráter de inimigo da época.

A revolução Industrial nos aproxima um pouco mais do contexto atual, visto que em razão do boom populacional ocorrido nas cidades durante esse período, o indesejável era justamente o pobre, proletariado, que teria saído da zona rural para tentar uma melhor fonte de renda na área urbana. Sendo assim, eram colocados para morrer na penitenciaria com objetivo de aliviar a grande massa populacional existente nas cidades.

A partir da segunda metade do século XX, a sociedade pós-industrializada passou a sofrer consideráveis mudanças no seu modo de vida e, como ja visto anteriormente, a política de combate a criminalidade passa a ser demanda imediata desse meio social vulnerável, tomado pelo medo. Assim, o criminoso sobrevém como inimigo comum que deve ser submetido a toda violência e repressão estatal, uma vez que configura uma constante ameaça a ordem social. De acordo com HASSEMER apud BONFIM (1990, p. 113):

Acontecendo isso, tem-se a velha visão da criminologia clássica, que concebia o delito como um enfrentamento formal, simbólico e direito entre dois rivais o Estado e o infrator -, os quais travam um maniqueísta conflito de bem contra o mal. Um personificava o lado bom da sociedade, sem maculas, perfeito, congregando os justos e pacíficos; o outro o perigoso delinquente, temos a ser extirpado o mais rápido possível, com o fito de sanear novamente o corpo social. 
Dessa forma, ocorre uma clara divisão da sociedade entre os cidadãos e os inimigos, de forma a este ultimo deve ser destinado toda forma de violência e coerção em razão do perigo que representa a ordem social. Assim, o Estado atua de forma preventiva em relação a esses sujeitos, amparado pelo discurso de preservação a segurança publica. Ao ingressar no cárcere, portanto, esses sujeitos não mais são considerados potenciais inimigos, e sim inimigos declarados, assim, a vida no ambiente prisional revela muito do que é ser excluído do Estado e ter a vida e dignidade julgadas como descartáveis.

Nas palavras de Zaffaroni:

Os indesejáveis continuam a ser eliminados por meio de medidas administrativas, penas desproporcionais (para reincidentes) e internação em cárceres marcados por altíssimos índices de violencia, de mortalidade hétero e autoagressiva e de morbidade, ou seja, alta probabilidade de eliminação física, paralelamente as execuções policiais e parapoliciais sem processo.

O massacre do Carandiru ocorrido em 2 de Outubro de 1992 é exemplo dessa atuação repressiva de segurança publica contra os encarcerados, uma vez que foi um dos maiores extermínios ja ocorridos dentro de uma prisão Brasileira, no qual 111 pessoas foram mortas pelos agentes do Estado. A letra da música Diário de um Detento, escrita por Mano Brown em contribuição com um ex-detento, Jocenir, aborda a violência cometida nesse dia.

Segue o trecho da música.

Cachorros assassinos, gás lacrimogêneo...

quem mata mais ladrão ganha medalha de prêmio!

O ser humano é descartável no Brasil.

Como modess usado ou bombril.

Cadeia? Claro que o sistema não quis.

Esconde o que a novela não diz.

Ratatatá! sangue jorra como água.

Do ouvido, da boca e nariz.

O Senhor é meu pastor...

perdoe o que seu filho fez.

Morreu de bruços no salmo 23,

Sem padre, sem repórter.

Sem arma, sem socorro.

Vai pegar HIV na boca do cachorro.

Cadáveres no poço, no pátio interno.

Adolf Hitler sorri no inferno!

O Robocop do governo é frio, não sente pena.

Só ódio e ri como a hiena.

Portanto, esse status de inimigo imputado às pessoas em situação de cárcere é revelado a partir das diversas formas de violência nas quais estão sujeitos dentro das penitenciárias, assim como pela adoção de medidas preventivas para conter esses indivíduos, como é o caso das 
prisões provisórias.

De acordo com levantamentos do DEPEN do ano de 2016, 55\% desses presos possuem entre 18 e 29 anos, 64\% são de etnia negra e 51\% não chegaram a completar o ensino fundamental, logo, através dessa pesquisa empírica sobre o perfil da massa carcerária no Brasil, fica claro quem foram os selecionados para representar a classe de inimigos do Estado atualmente.

Esse distanciamento do Estado de Direito em relação aos encarreirados faz com que, na falta de um Estado legitimo, as necessidades desses sujeitos sejam supridas por uma forma alternativa de organização dentro das penitenciarias, criada por esses próprios sujeitos: $\mathrm{O}$ crime organizado. Segundo o dossiê PCC, sistema prisional e gestão do novo mundo do crime no Brasil "o crime organizado se apresenta como o representante dessa massa criminal que se defende da violência da ordem social vigente."

Essas organizações, portanto, atuam como uma forma de Estado Paralelo que promovem a proteção e organização dessas pessoas esquecidas pelo Estado de Direito, de forma que quanto maior é esse esquecimento e relativização dos direitos dos encarcerados, mais fortalecido fica o crime organizado, uma vez que passam a se organizarem para sobreviverem a essa guerra declarada da qual fazer parte.

\section{DESENVOLVIMENTO DO PRIMEIRO COMANDO CAPITAL (PCC)}

Como já visto, foi através das estratégias de segurança pública adotadas pelo Estado que se iniciou o processo de encarceramentos em massa no Brasil. A população prisional aumentou consideravelmente, mais do que a própria estrutura dos presídios suportava, de forma que a implementação de uma política de segurança pública cada vez mais punitivista levou ao boom da massa carcerária em um período relativamente curto de tempo, sendo grande parcela dessa população, inclusive, presa de forma provisória. De acordo com os dados tirados do dossiê PCC, Sistema Prisional e Gestão do novo mundo do crime no Brasil "Em São Paulo, as 36 unidades e os 32 mil presos de 1993 se multiplicaram, formando atualmente um vasto universo com 168 unidades e mais de 220 mil pessoas, com quase o dobro de habitantes de sua capacidade, o déficit em agosto de 2016 era de 94 mil vagas. (MANSO; DIAS, 2017, p. 15)".

Nesse contexto, a estrutura carcerária não conseguiu acompanhar a grande massa populacional que ingressava nesses estabelecimentos, o que levou a uma significativa desproporção entre os agentes prisionais e a quantidade de presos, na medida em que ainda era 
mantida a mesma estrutura de um período em que a população carcerária permanecia estável.

Com esse fenômeno, os agentes prisionais passaram a ficar cada vez mais distantes dos detentos, uma vez que a desproporção entre eles dificultava uma maior fiscalização. Assim, os encarreirados adquiriram mais privacidade e contato direito uns com os outros, proporcionando uma maior facilidade de articulação e organização entre si. DIAS e MANSO (2017, p. 15) explicam como se deu esse processo:

A expansão do sistema prisional a partir da construção de novas unidades sem que houvesse proporcionalmente a contratação de novos servidores teve como efeito o progressivo afastamento dos agentes penitenciários dos espaços de convivência dos presos, especialmente as celas e o pátio de sol, que ganharam mais autonomia na de definição e mediação das regras cotidianas dos presídios. Pouco a pouco a gestão das prisões foi sendo compartilhada entre administração prisional (cuja gestão é feita dos pavilhões para fora) e os presos vinculados às facções (cuja gestão é feita do pavilhão para dentro), numa espécie de "privatização" disfarçada da gestão penitenciária (DIAS; BRITO, 2017). Nesse processo o controle social que se estabelece dentro dos raios e das celas é imposto pelos próprios presos, havendo pouca ou nenhuma intervenção da administração estatal.

O Primeiro Comando Capital foi criado em 1993 por um grupo de 8 presos do Centro de Reabilitação Penitenciária de Taubaté, destinada a prisioneiros de alta periculosidade, também conhecida pelos maus tratos e todas as formas de violações aos direitos dos detentos que lá residiam. O tratamento desumano somado a ausência de devida fiscalização foi o que levou o grupo de detentos a se unir contra as formas de violência na qual eram submetidos pelo poder publico. O $13^{\mathrm{a}}$ artigo do estatuto de fundação do grupo PCC deixa claro essa necessidade de autoproteção dos encarreirados.

Temos que permanecer unidos e organizados para evitar que ocorra novamente um massacre, semelhante ou pior ao ocorrido na Casa de Detenção (...), massacre este que jamais será esquecido na consciência da sociedade brasileira. Porque nós do Comando vamos sacudir o sistema e fazer essas autoridades mudar a prática carcerária desumana, cheia de injustiça, opressão, tortura e massacres nas prisões.

Portanto, o Primeiro Comando Capital nasce dessa necessidade de proteção do Estado, uma vez que este configura uma constante ameaça à população carcerária. $\mathrm{O}$ estigma do inimigo e a forma de tratamento destinada a essas pessoas, em razão desse estigma, as levaram a incorporarem tal identidade, de forma que a união entre eles em busca de maior dignidade dentro do cárcere possibilitou um processo de auto-organização com objetivo de combate ao 
poder estatal. DIAS e MANSO (2017, p. 22) esclarecem que:

Os confrontos e as lutas deveriam ser reservados unicamente para a relação com o Estado opressor. A confrontação ao poder estatal, por sua vez, só seria possível numa situação de união e de fortalecimento mútuo dos encarcerados e de todos aqueles que fazem parte do "mundo do crime".

Assim, o PCC consolidou-se como representante dessa massa criminal obrigada a sofrer com as arbitrariedades do poder publico. Aproveitando o contexto propicio existente dentro das penitenciarias a época, em razão do aumento na quantidade de detentos, o PCC surge como um Estado paralelo para suprir a ausência do Estado legitima dentro dos estabelecimentos prisionais, visando, principalmente, reestabelecer a paz entre os detentos.

Foi com esse ideal de união entre os presos que o Primeiro Comando Capital se espalhou pelos diversos Estados da federação e funciona como um verdadeiro

Estado dentro dos estabelecimentos prisionais, na medida em que seus representantes que ditam as regras de convivência e as formas de organização interna. Atualmente, o Ministério Público estima que o PCC exerça autoridade entre 90\% dos presos em São Paulo.O mapa abaixo deixa claro a hegemonia do Primeiro Comando Capital nos Estados brasileiros:

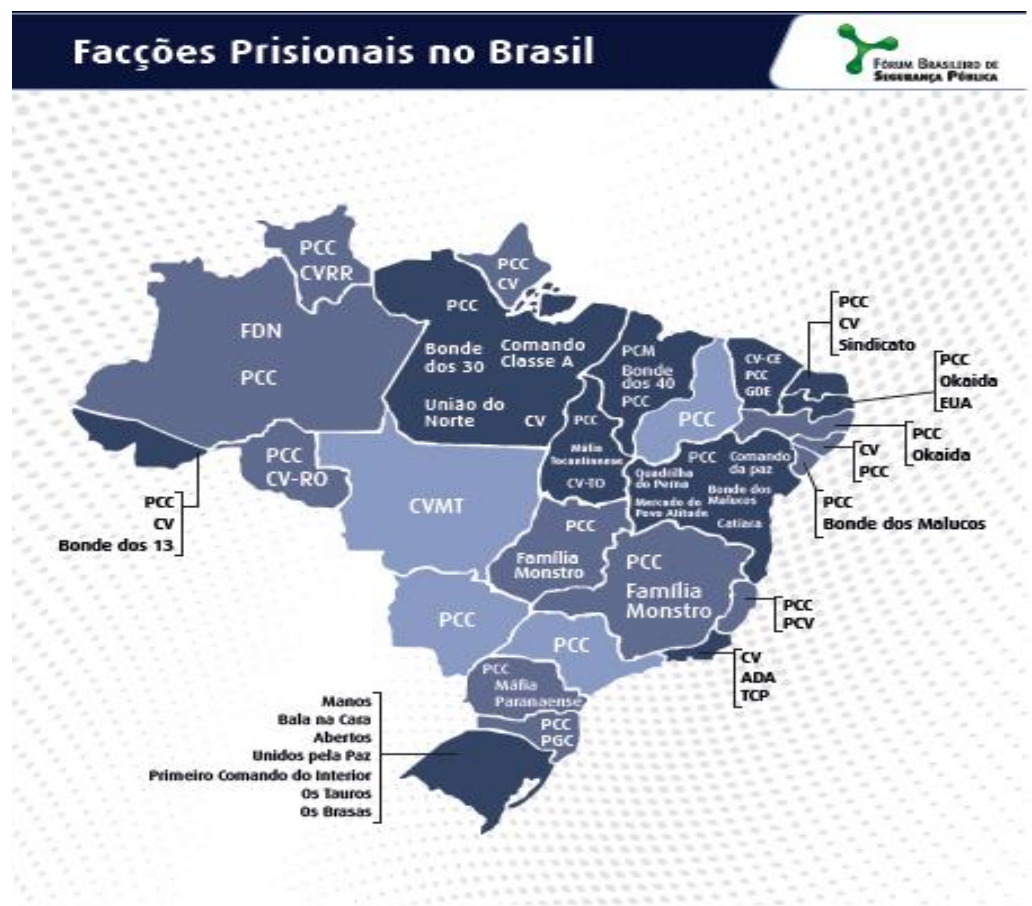

Fonte: Anuário Brasileiro de Segurança Pública, 2014-2017. 
Essa expansão para fora dos estabelecimentos prisionais se deu, principalmente, no início dos anos 2000 com a popularização dos telefones celulares. Através desse novo recurso, portanto, os presos puderam com mais facilidade contatar também com detentos de outros presídios para articular rebeliões e deter o controle do mercado de drogas também do lado de fora, assim, o ambiente prisional se tornou lugar estratégico para articulação de crimes. De acordo com FELTRAN (2010a, 2010b) um modelo aproximado de organização do PCC se deu da seguinte forma:

Essas sintonias foram distribuídas por pontos territoriais estratégicos do estado de São Paulo - organizadas de cima para baixo, a partir do código de discagem (DDD), afunilando em regiões menores até chegar aos bairros -, cumprindo duas funções principais. A disciplina, que tenta preservar a estabilidade local, mantendo um relacionamento adequado com autoridades e comunidade, e a financeira, que organiza o comércio de drogas. Homicídios passaram a ser proibidos, a não ser com autorização e mediação dos integrantes do PCC. Essas mediaçães são chamadas também de "debates" ou "tribunais do crime" (FELTRAN, 2010).

Foi assim que em agosto de 2001 o PCC conseguiu organizar a primeira mega rebelião da história na cidade de São Paulo, em que 29 prisões se rebelaram simultaneamente. Assim, a facção mostrou para sociedade sua forca e poder de articulação ao conseguir parar a maior metrópole do Brasil por 3 dias. Além desse episódio, em maio de 2006 o PCC também liderou motins e rebeliões em nada menos que 22 presídios do Estado, no qual houve uma série de ataques aos órgãos de segurança pública e a sociedade civil.

Com essa expansão do crime organizado houve a intensificação da criminalidade por todo o país, principalmente através do tráfico de drogas. Segundo relatório das Nações Unidas sobre Drogas e Crime- UNODC (ONU, 2016), o consumo de crack e cocaína só aumentou no Brasil a partir dos anos 2000. Na América Latina esse aumento foi de mais de 50\% no consumo de cocaína só entre os anos de 2010 e 2012.

Atualmente, o que se constata é uma verdadeira guerra entre os agentes do estado e o crime organizado em diversas partes do país, dentro e fora dos presídios. Essa constante disputa, também denominada de guerra as drogas, traz consequências devastadoras a toda população na medida em que o entorno também é atingido por esse conflito, principalmente se tratando de áreas periféricas.

De acordo com o Ministério da Justiça e Secretaria da Administração Penitenciária o número de presos por trafico de drogas no Estado de São Paulo aumentou 508\% entre os anos 
de 2005 e 2017, nesse mesmo período a população prisional do estado aumentou em 64\%. O empenho do Estado brasileiro em combater o tráfico de drogas é, portanto, justificado pela estrutura criminal que há por trás desse mercado, uma vez que o tráfico de drogas é o principal combustível do crime organizado. Sendo assim, o combate não se da somente ao tráfico em si, mas principalmente aos sujeitos que estão por trás dele.

\section{PRINCÍPIO DA DIGNIDADE, IGUALDADE E PROPORCIONALIDADE}

Ao fazer uma relação entre o Direito Penal do Inimigo e os princípios fundamentais previstos pela Constituição Federal, é possível verificar grande conflito entre um e outro, principalmente ao considerar o princípio da dignidade da pessoa humana, da proporcionalidade das penas e da igualdade.

Primeiramente, porque o Direito Penal do Inimigo é baseado na ideia do não cidadão, sendo assim, o agente do delito de alta periculosidade é privado de direitos e garantias básicas, ao passo que a eles não é aplicada a pena conforme dita o código penal, tampouco o procedimento de acordo com o devido processo legal, e sim uma espécie de coação violenta, uma vez que as penas comuns não são consideradas eficazes para deter tais indivíduos. Por outro lado, aos cidadãos comuns que comentem crimes de relevância moderada, as garantias constitucionais e processuais são resguardadas. Tal forma de tratamento diferenciado entre um e outro tem como consequência a separação dos indivíduos entre os que merecem tratamento de cidadão, e os não cidadãos que devem ser abolidos do Estado.

Nesse sentido, também entra em cena o princípio da igualdade, uma vez que sugere a segregação da sociedade entre os cidadãos e não cidadãos. Aos primeiros, portanto, é resguardado um tratamento digno, ao passo que os últimos são submetidos a uma serie de artifícios cruéis, em total desacordo com a constituição democrática.

Observa-se assim que a penalização não é pautada pelo nível de culpabilidade do agente e sim pelo estigma de inimigo que ele carrega, uma vez que aos inimigos são implicadas medidas de segurança totalmente arrazoáveis aos princípios e garantias constitucionais e desproporcionais aos danos causados.

A Proporcionalidade das penas presa justamente pelo equilíbrio entre a pena cominada ao agente e a lesão causada pela pratica delitiva. Sendo assim, o princípio é pautado pela proporcionalidade entre a gravidade da conduta, determinada pela relevância do bem jurídico 
que é atingido com a prática delitiva, e a pena imputada ao agente do delito. Assim, aos crimes com maior periculosidade serão destinadas as maiores penas. Entretanto, por mais gravosa que seja a conduta criminosa, a dignidade da pessoa humana vem limitar as formas de punições do Estado como meio de garantir o tratamento humanizado mesmo aos agentes de delitos mais graves. Em outras palavras, mesmo aos indivíduos mais ameaçadores é resguardada a dignidade, de forma que deve ser mantida razoabilidade entre a pena cominada e as garantias constitucionais, assim como a proporcionalidade entre esta e a lesão causada.

Portanto, a destinação de penas extremamente autoritárias e cruéis a uma classe específica de pessoas é de total discordância com o que prevê a constituição federal, na medida que a dignidade da pessoa humana é direito fundamental indisponível, destinado a todos, sem distinção.

\section{CONSIDERAÇÕES FINAIS}

A partir dessa analise podemos concluir que a teoria aplicada no Brasil acaba sendo apenas um viés do que foi criado por Jakobs, ao passo que a realidade do cárcere brasileiro revela muito do que menciona Zaffaroni, na medida em que o Estado estende sua atuação coercitiva a qualquer um que pratique uma conduta ameaçadora, o que é constatado a partir do processo de encarceramentos massivos iniciados no final do século XX, assim como pelo abuso das prisões preventivas fortalecido também nesse período. A atuação estatal extremamente violenta, assim como, o descaso com as necessidades básicas do sujeito encarcerado, conduz, portanto, a supressão do Estado de Direito através do que Schmitt menciona como guerra suja, que é justamente esse confronto do Estado contra os inimigos no qual não há regras a serem seguidas nem direitas a serem resguardados.

Assim, o tratamento desumano só faz nascer, entre os que são submetidos a isso, um sentimento de vingança, que é concretizado pelo surgimento do crime organizado como forma de organização paralela dentro das penitenciaria, visando justamente a proteção dos presos e o combate ao poder Estatal. Nesse aspecto, observamos que a aplicação do Direito penal do Inimigo no cárcere gera efeito totalmente contrário ao que Jakobs menciona, de preservação a segurança pública e a manutenção da autoridade estatal através da eliminação de um perigo. Ao passo que, ao ingressar no estabelecimento prisional o detento já é automaticamente inserido nessa estrutura de criminalidade organizada, de forma que, quanto mais se prende, mais membros o Estado envia a essa estrutura criminosa. DIAS e MANSO (2017, p. 25) confirmam 
esse raciocínio ao afirmarem que:

Em relação às opções políticas do governo federal -e igualmente para os estados- apostou-se no amplo encarceramento e em operações violentas da polícia ostensiva, que teve como principal efeito o aumento da violência e da multiplicação das facções pelo Brasil.

Portanto, foi através da aplicação de um direito penal não humano que os detentos passaram a atuar no combate ao poder coercitivo estatal com o surgimento das facções criminosas, o que levou ao aumento da criminalidade ligada principalmente a expansão do tráfico de drogas, comandado por essas facções. Atualmente o que se identifica é uma verdadeira guerra entre o Estado e o crime organizado, popularmente chamada guerra as drogas, que coloca em risco toda a sociedade.

Uma vez que o poder do Estado se encontra em constante ameaçado por essa estrutura paralela, o combate ao tráfico de drogas torna-se uma das principais bandeiras do poder estatal, e um dos principais focos de atuação da polícia. Tal fato nos remete justamente ao inimigo definido por Hobbes, que é aquele que contesta a autoridade do estado e ameaça o ordenamento jurídico, nesse caso através do fortalecimento de um Estado paralelo altamente organizado. Assim, o Estado justifica a atuação autoritária e coercitiva para com os sujeitos que fazem parte dessa estrutura, destituindo-os do status de cidadão e aplicando-os o de inimigo.

Portanto, considerando que uma política de combate à criminalidade baseada no Direito Penal do Inimigo só resultou no fortalecimento da mesma, através da consolidação do crime organizado, é imprescindível uma mudança nessa forma de atuação estatal, na medida em que declarar guerra a criminalidade apenas contribui para que os que estão do outro lado incorporem essa identidade de inimigo do Estado e busquem formas para contra atacar.

Sendo assim, a supressão da criminalidade só será efetiva quanto às próprias autoridades cessarem com essa acumulação de violência através de condutas extremamente violentas e repressivas, dado que permanecer em constante conflito com os agentes criminosos só estimula essa guerra na qual toda a sociedade está inserida.

\section{REFERÊNCIAS BIBLIOGRÁFICAS}

BARCELLOS, Ana Paula de. Violência Administrativo, v. 254, p. 39-65, 2010. urbana, condições das prisões $e$ Disponível em dignidade humana. Revista de Direito http://bibliotecadigital.fgv.br/ojs/index.ph 
p/rda/article/view/8074, acesso em 31 de outubro de 2019.

BRASIL, Instituto de Pesquisa Econômica Aplicada. Atlas da violência, disponível em http://www.ipea.gov.br/atlasviolencia/, acesso em 31 de outubro de 2019.

BRASIL. A maior rebelião da história. Jornal (impresso) $O$ Estado de São Paulo. Disponível em https://brasil.estadao.com.br/blogs/arquiv o/a-maior-rebeliao-da-historia/, acesso em 10 de novembro de 2019.

BRASIL. Anuário Brasileiro de Segurança Pública 2014-2017. Fórum Brasileiro de Segurança Pública, Ed. Especial 2018. Disponível em http://www.forumseguranca.org.br/wpcontent/uploads/2018/09/FBSP_ABSP_e dicao especial estados faccoes 2018.pd f, acesso em 10 de novembro de 2019.

BRASIL. Estatuto de PCC. Disponível em

https://www.imprensaoficial.com.br/DO/ BuscaDO2001Documento_11_4.aspx?lin k=/1997/legislativo/maio/20/pag_0005_9 C6DMSGM1SAKCe66LSJGHRCHSHF. pdf \&pagina $=5 \&$ data $=20 / 05 / 1997 \&$ cader no=Legislativo\&paginaordenacao $=10005$ , acesso em 10 de novembro de 2019.

BRASIL. Levantamento Nacional de Informações Penitenciárias: INFOPEN junho de 2014. Ministério da Justiça, Departamento Penitenciário Nacional, 2014. Disponível em https://www.justica.gov.br/news/mjdivulgara-novo-relatorio-do-infopennesta-terca-feira/relatorio-depen-versaoweb.pdf. Acesso em 10 de novembro de 2019.

BRASIL. Levantamento Nacional de Informações Penitenciárias: INFOPEN. SANTOS, Thandara (Org.). ROSA, Maria Inês da (Colab.), et al. Brasília:
Ministério da Justiça e Segurança Pública. Departamento Penitenciário Nacional, 2017. Disponível em: http://depen.gov.br/DEPEN/noticias1/noticias/infopen-levantamentonacional-de-informacoes-penitenciarias2016/relatorio_2016_22111.pdf. Acesso em 10 de novembro de 2019.

BRASIL. Maior ataque do PCC faz 32 mortos em SP. Jornal (digital) Folha de São Paulo. Disponível em https://www1.folha.uol.com.br/fsp/cotidia n/ff1405200601.htm. Acesso em $10 \mathrm{de}$ novembro de 2017.

FELTRAN, Gabriel de Santis. Margens da política, fronteiras da violência: uma ação coletiva das periferias de São Paulo. Lua Nova, No. 79, 2010b, pp. 201-233.

FELTRAN, Gabriel de Santis. The management of violence on the periphery of São Paulo: A normative apparatus repertoire in the "PCC era". Vibrant: Virtual Brazilian Anthropology, v.7, n. 2, 2010a.

HASSEMER. El Destino de Los Derechos Del ciudadano em um Derecho Penal "Eficazz". Buenos Aires: Doctrina Penal, Ano 13, 49-52, Tradução: Francisco Muñoz Conde, 1990.

MANO BROWN. Diário de um Detento. São Paulo: Cosa Nostra, 1997. Disponível em http://g1.globo.com/Noticias/Musica/0,, MUL169176-7085,00.html.

MANSO, Bruno Paes; DIAS, Camila Nunes. PCC, sistema prisional e gestão do novo mundo do crime no Brasil. Revista Brasileira de Segurança Pública, v. 11, n.2, 10-29, Ago/Set,. São Paulo, 
2017.

ORGANIZAÇÃO DAS NAÇÕES UNIDAS. Relatório das Nações Unidas sobre Drogas e Crime- UNODC, 2016.

SANTOS, Iris Gomes dos; GONTIJO, José Geraldo Leandro; AMARAL, Ernesto F. L.. A política de segurança pública no Brasil: uma análise dos gastos estaduais (1999-2010). Opin. Publica, Campinas, v. 21, n.1, p. 105-131, Apr. $2015 . \quad$ Disponível em http://www.scielo.br/scielo.php?script=sc i_arttext\&pid=S010462762015000100105\&lng=en\&nrm=iso, acesso em 31 de outubro de 2019.
VELASCO, Clara; REIS, Thiago; et al. Superlotação aumenta e número de presos provisórios volta a crescer no Brasil. Jornal (digital) G1 e GloboNews. Disponível em:

https://g1.globo.com/monitor-daviolencia/noticia/2019/04/26/superlotacao -aumenta-e-numero-de-presosprovisorios-volta-a-crescer-nobrasil.ghtml. Acesso 11 de agosto de 2019.

ZAFFARONI, Raúl E. $O$ inimigo no Direito Penal. Ed. Revan, Col. Pensamento Criminológico, n. 14, Instituto Carioca da Criminologia. Rio de Janeiro, 2007.

NUNES, I. N. Uma Análise Sobre o Desenvolvimento do Primeiro Comando Capital a Partir da Efetivação do Direito Penal do Inimigo na Realidade do Cárcere Brasileiro. Complexitas - Rev. Fil. Tem. Belém, v. 4, n. 1, p. 85-101, jan./jun. 2019. Disponível em: http://www.periodicos.ufpa.br/index.php/complexitas/article/view/8048>. Acesso em: 30 de janeiro de 2020. 